
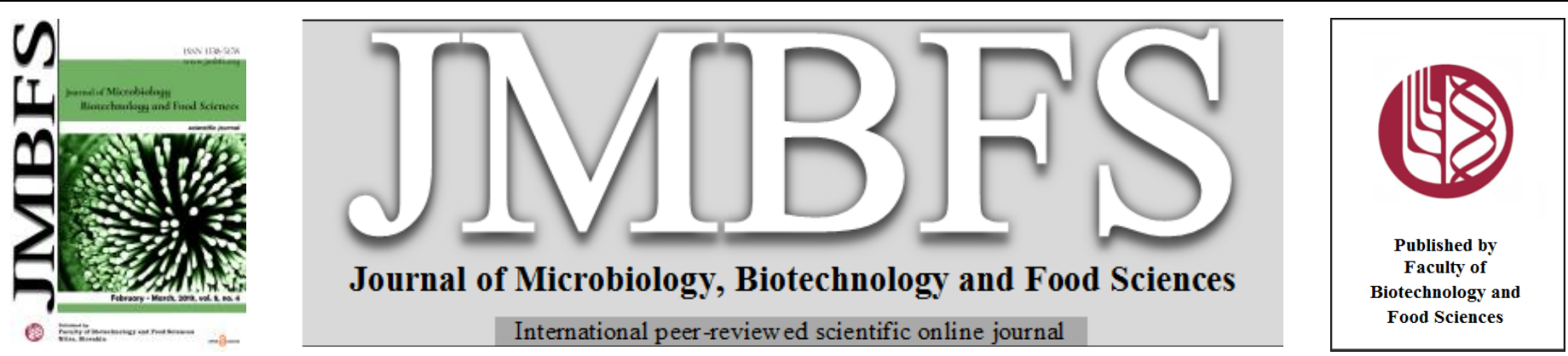

\title{
STUDY OF CYNARA CARDUNCULUS (ARTICHOKE) STEM AND LEAVE AQUEOUS EXTRACT EFFECTS ON BIOCHEMICAL PARAMETERS IN RATS FED WITH HIGH-FAT-DIET AND VITAMIN C-SUPPLEMENT
}

\author{
Abdelkrim Berroukche ${ }^{*, 1}$, Yasmina-Mokhatria Boufadi ${ }^{2}$, Hafsa Dellaoui ${ }^{I}$, Wassila Lansari ${ }^{1}$ and Imen Zerarki $^{1}$ \\ Address(es): \\ ${ }^{1}$ Research Laboratory of Water Resources and Environment, Biology Department, Faculty of Science, University Tahar-Moulay of Saida, 2000 Algeria. \\ ${ }^{2}$ Laboratory of Beneficial Microorganisms, Functional Food and Health (LMBAFS), Faculty of Natural Sciences and Life, University of Abdelhamid Ibn Badis, \\ Mostaganem, 27000 Algeria.
}

*Corresponding author: kerroum1967@yahoo.fr

doi: 10.15414/jmbfs.2019.8.5.1145-1149

\section{ARTICLE INFO}

Received 7. 7. 2018

Revised 15. 11. 2018

Accepted 3. 12. 2018

Published 1. 4. 2019

Regular article OPEN $\partial_{\text {ACCESS }}$

\begin{abstract}
Cynara cardunculus (CC), belonging to the family of artichokes, is rich in polyphenols and flavonoids. This medicinal plant has shown its preventive effects against metabolic disorders. This study aimed to assess the effects of CC stems (CCS) and CC leaves (CCL) decoctions on metabolic parameters in rats fed with High-Fat-Diet and Vitamin C-supplement. This study underwent on 30 male adult rats divided into 5 groups; Controls, HFD, HFD-VC, HFD-CCS and HFD-CCL. Body weight and biochemical parameters such as blood glucose, cholesterol, triglycerides and hepatic transaminases (GOT \& GPT) were measured by spectrophotometric analysis methods during an experimental period (30 days). Decreased body weights were observed in HFD-CCS (176.93 g) and HFD-CCL (173.2 g) compared to HFD-VC (216.63 g). Significant changes were observed regarding blood glucose, total cholesterol, cholesterol-HDL and triglycerides in HFD-CCS $(0.84 \pm 0.03,1.01 \pm 0.07,1.21 \pm 0.05$ and $0.64 \pm 0.03 \mathrm{~g} / \mathrm{L}$ respectively $)$ and HFD-CCL $(0.85 \pm 0.02,0.89 \pm 0.03$, $1.42 \pm 0.05$ and $0.52 \pm 0.02 \mathrm{~g} / \mathrm{L})$ compared to HFD-VC $(1.32 \pm 0.02,1.3 \pm 0.05,0.76 \pm 0.02$ and $0.86 \pm 0.08 \mathrm{~g} / \mathrm{L})$. Liver function was characterized by decreased transaminase activities of GOT and GPT in HFD-CCS (22.6 and 19.6 IU / L) and HFD-CCL (12.6 and 10.3 IU / L) compared to HFD-VC (112 and 73.6 IU / L). Cynara cardunculus showed beneficial effects against biochemical disorders induced by high-fat-diet better than vitamin $\mathrm{C}$ supplement. Stem and leave decoctions showed complementary activities respectively hypoglycemic and hypocholesterolemic.
\end{abstract}

Keywords: Cynara cardunculus; flavonoids; vitamin C; blood glucose; cholesterol; triglycerides

\section{INTRODUCTION}

Foods, imported from the west, influenced the diet of our society allowing the emergence of diseases characterized by metabolic disorders namely hyperglycemia and hyperlipidemia (Cho et al., 2010). Cardiovascular disease, type 2 diabetes, hypertension and obesity have a common risk factor that is a diet rich in calories (Bastaki, 2005). The long-term use of drugs, to prevent defects, could be a source of toxicity adding to the heavy burden of these pathologies. The case of vitamin $\mathrm{C}$ often used against colds, flu and headaches that is not highly toxic but is known for its side effects such as nausea, diarrhea and digestive noises (Institute of Medicine, 2000). The use of medicinal plants is only a relief and natural remedy for the patient who became a prey to synthetic and toxic molecules produced by a lucrative wild pharmacological industry. It is reasonable to substitute drugs and chemicals by plants with natural and therapeutic interests. Among the plants grown in Algeria, this report was focused on Cynara cardunculus (Artichok). This plant, cultivated in the Mediteranean areas, belongs to the Asteraceae family (Lombardo et al., 2010). Algeria is a big producer of artichokes in North Africa with 40000 tons harvested in the year 2005 (INRA, 2006). It has an invaluable dietary value. It's highly consumed and healthy product with easy digestion. In addition to iron, calcium and vitamins, Cynara cardunculus contains polyphenolic compounds, mainly caffeoylquinic acids and flavonoids (Lombardo et al.,2010; Pandino et al., 2011 ). It also contains triterpenes and sesquiterpenes (Ramos et al., 2013). Amounts of these bioactive compounds depend on climatic, environmental and genetic factors and particularly on plant parts of Artichoke. Caffeic acids derivatives, namely hydroxycinnamic acids, are found at higher amounts in leaves and stems (Pandino et al., 2011). These molecules have biological effects such as inhibition of lipoxygenase and acting as antioxidants scavenging reactive oxygenated species (ROS) or free radicals resulting from oxidative stress (Fritsche et al. 2002). Cynarin, major compound of caffeoylquinic acid derivatives class, showed hepato-protective effects (Perez-Garcia et al., 2000). This category of molecules has also antibacterial activities against some pathogens like Staphylococcus aureus and Escherichia coli. These preventive effects are due mainly to the high level of phenolic components in the leaves (Yuan et al., 2014). Cynarosides, important molecules of flavonoid class, showed hypolipidemic activity (Fritsche et al., 2002). Other antioxidant compounds, as apigenin, have a potential antimicrobial activity (Rossoni $\boldsymbol{e t}$ al., 2005). To day, there is few data on the preventive and curative effects of artichokes cultivated in Algeria. The objective of our study was to assess the effects of Cynara cardunculus stems and leaves (CCS and CCL respectively) decoctions on biochemical parameters in rats fed with high-fat-diet and vitamin C-supplement.

\section{MATERIAL AND METHODS}

\section{Chemicals}

Vitamin C, or ascorbic acid (1000 g) used as drug, was purchased from a local pharmacy. This chemical contains some excipients as follow; sodium bicarbonates, anhydride citric acid, sucrose, sodium saccharin, macrogol 6000 , sodium benzoate, orangey yellow S (E110) and orange aroma.

\section{Plant (Cynara cardunculus)}

The artichoke (Cynara cardunculus) was purchased from a local market and stored at $4{ }^{\circ} \mathrm{C}$ until used. The plant was identified by botanist affiliated to biology department, faculty of science, Saida University.

\section{Preparation of plant aqueous extracts (decoction)}

Amounts of 125 g Cynara cardunculus leaves (CCL) and $125 \mathrm{~g}$ Cynara cardunculus stems (CCS) were dried, powdered, dissolved in $1000 \mathrm{~mL}$ of distilled water, heated for $30 \mathrm{~min}$ and decanted for 15 hours. The aqueous extracts were filtrated with Whatmann paper $\mathrm{N}^{\circ} 11$ then stored at $4{ }^{\circ} \mathrm{C}$ until use (Fig 1 and Fig 2). 


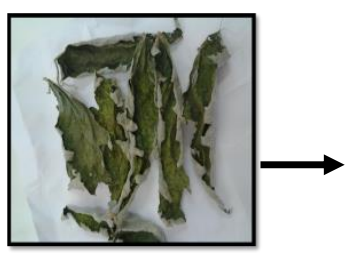

A

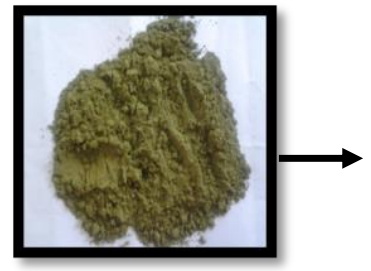

B

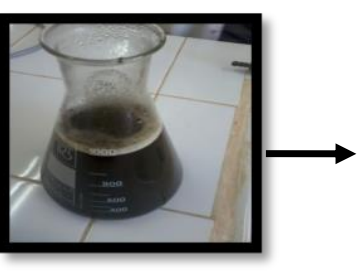

C

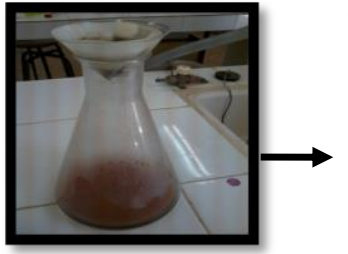

D

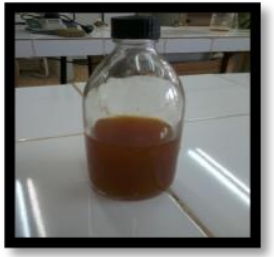

$E$

Figure 1 Steps of the preparation Cynara cardunculus leaves aqueous extract.

A: Cynara cardunculus (CC) dried leaves, B: CC powdered leaves, C: obtained CC leaves aqueous extract, D: Filtration, E: Filtrate stored.

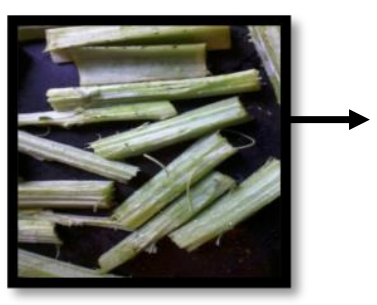

A

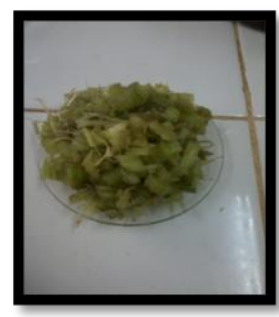

B

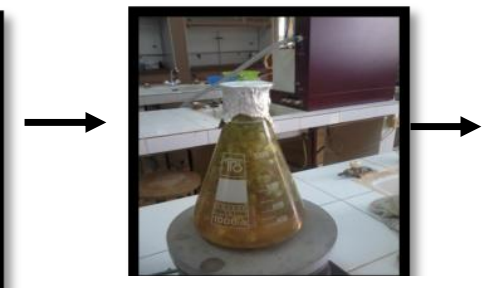

C

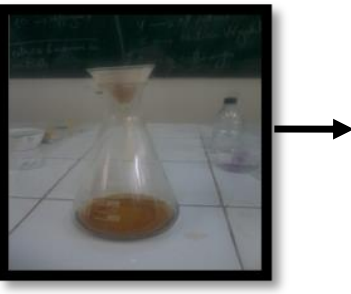

D

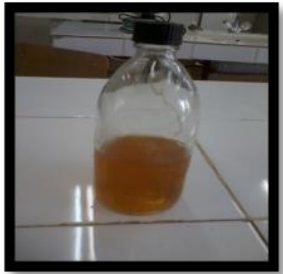

$E$

Figure 2 Steps of the preparation Cynara cardunculus stems aqueous extract.

A: Cynara cardunculus (CC) fresh stems, B: CC stems cut in pieces, C: obtained CC leaves aqueous extract, D: Filtration, E: Filtrate stored.

\section{Experimental design}

Thirty adult male rats, weighting $150-190 \mathrm{~g}$, were housed in plastic cages in the animal of biology department, under controlled conditions $\left(25^{\circ} \mathrm{C}, 12\right.$ hours light/dark cycle) and had access to food and water ad libitum. Animals were divided into five groups (6 rats / group); Controls: received standard diet (100 g /day) and tap water, HFD: fed with high fat diet (200 g / day), HFD-VC: vitamin
C (200 mg) added to high fat diet, HFD-CCS: orally administered with $2 \mathrm{~mL} \mathrm{CC}$ stems aqueous extract ( $125 \mathrm{mg} / \mathrm{mL} /$ day $)$ for 30 days, HFD-CCL: orally administered with $2 \mathrm{~mL} \mathrm{CC}$ leaves aqueous extract $(125 \mathrm{mg} / \mathrm{mL}$ ) in the same conditions (Fig 3). LD50 of vitamin C, orally administered to rats, is about 11900 $\mathrm{mg} / \mathrm{kg}$ (Uzun et al., 2009; Animal toxins, website accessed July 16, 2018). The high-fat-diet (or cafeteria diet) consisted of standard diet $(50 \%)$ and a mixture $(50 \%)$ of sausage, biscuits, cheese, chips, peanut, chocolate in proportions 2: 2: 2: $1: \quad 1: \quad 1 \quad$ (Pouteau et al., 2008).

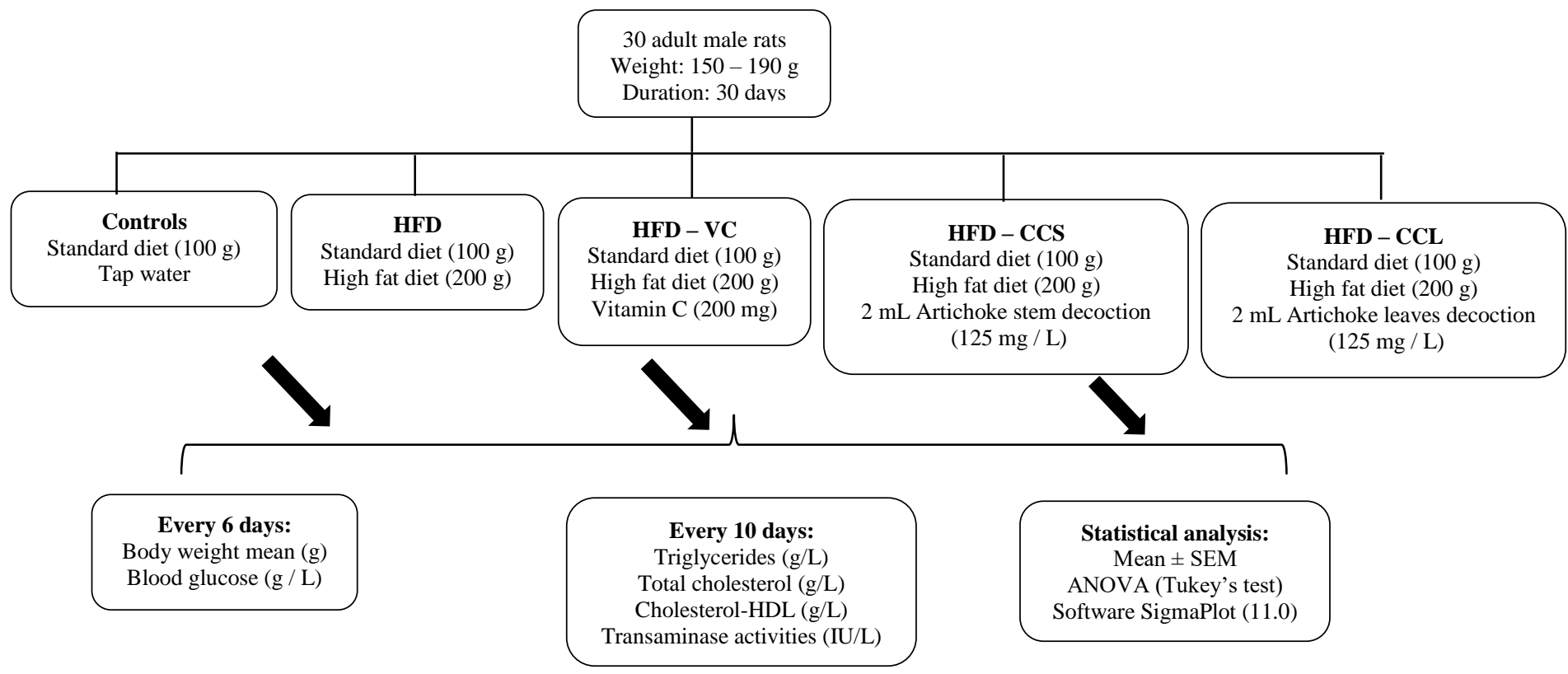

Figure 3 Design of experiments on rats fed with high-fat-diet and treated with vitamin C, Cynara cardunculus stem and leave aqueous extracts (decoction).

\section{Anthropometrical and biochemical studies}

Body weight mean of animals and blood glucose were recorded every 6 days. Food and water intake were monitored daily. Blood samples were taken from the tail tip of animals to measure glycaemia. Blood glucose levels $(\mathrm{g} / \mathrm{L})$ were determined by means of Accu-Chek glucometer. Blood glucose reactive test based on enzymatic reaction namely glucose oxidase method. Other biochemical parameters such as serum triglycerides, total-cholesterol, high-density lipoprotein-cholesterol (HDL-C) and transaminase activities were estimated every 10 days during the experiment duration (30 days) using an automateanalyzer "mini-VIDAS" (Bio Merieux Laboratories, Lyon, France).

\section{Statistical analysis}

Data were performed with SigmaPlot (version 11.0) software. Results were presented as a mean value \pm standard error of the mean (SEM) by using analysis of variance (ANOVA) followed with Tuckey's test to assess significant differences of results, with $p<0.05$ as the criterion of significance. 


\section{RESULTS AND DISCUSSION}

The effects of vitamin C and Cyrana cardunculus stem and leave decoctions on body weight and biochemical parameters were summarized in table 1. Body weight, blood glucose, triglycerides, total cholesterol and cholesterol-HDL were different and extremely significant between all groups of animals $(\mathrm{p}<0.01)$ (Fig 6,7,8 and 9). Results revealed, in HFD-CCS and HFD-CCL groups, decreased body weight mean $(176.9 \pm 1.6$ and $173.2 \pm 2.0 \mathrm{~g})$ compared to HFD-VC group $(216.6 \pm 2.2 \mathrm{~g})(\mathrm{Tab} 1)$. The results showed, in animals fed high-fat-diet and treated with CCS and CCL aqueous extracts at the dose of $125 \mathrm{mg} / \mathrm{L}$, a decreased blood glucose $(0.84 \pm 0.03$ and $0.85 \pm 0.02 \mathrm{~g} / \mathrm{L}$ respectively $)$ comparetively to HFD and HFD-VC groups $(1.43 \pm 0.08$ and $1.32 \pm 0.02 \mathrm{~g} / \mathrm{L}$ respectively) (Fig 6). In animals, fed with high-fat-diet and treated with vitamin $\mathrm{C}$ at dose of $200 \mathrm{mg}$, it was recorded a significantly increased blood triglycerides and total cholesterol $(0.86 \pm 0.08$ and $1.3 \pm 0.05 \mathrm{~g} / \mathrm{L}$ respectively) whereas in animals treated with Cyrana cardunculus part plant, namely CC stems and leaves, it was observed lowering blood levels of the same parameters $(0.64 \pm 0.03$ and $1.01 \pm 0.07 \mathrm{~g} / \mathrm{L})$ for CCS group and $(0.52 \pm 0.02$ and $089 \pm 0.03 \mathrm{~g} / \mathrm{L})$ for CCL group (Tab 1) (Fig 7 and 8). Results reported that blood cholesterol-HDL were statistically higher in CCS and CCL groups $(1.21 \pm 0.05$ and $1.42 \pm 0.05 \mathrm{~g}$ L) compared to HFD and HFD-VC groups $(0.46 \pm 0.06$ and $0.76 \pm 0.02 \mathrm{~g} / \mathrm{L})$ (Fig 9). The serum hepatic markers presented in table 1 showed extremely significant increase in transaminase serum activities in HFD and HFD-VC groups as follow $(68.6 \pm 2.9$ and $112.2 \pm 1.7 \mathrm{IU} / \mathrm{L}$ respectively) for GOT and $(34.6 \pm$ 2,0 and $73.6 \pm 3.3 \mathrm{IU} / \mathrm{L}$ ) for GPT markers unlike CCS and CCL groups which displayed decreased values as follows GOT $(22.6 \pm 0.5$ and $12.6 \pm 0.7 \mathrm{IU} / \mathrm{L}$ respectively) and GPT (19.6 \pm 0.5 and $10.3 \pm 0.6 \mathrm{IU} / \mathrm{L}$ respectively ) (Tab 1$)$.

Many studies have already shown that feeding animals with high fat diet exposed them to develop obesity associated with type 2 diabetes and this could be observed through increased blood glucose, triglycerides and cholesterol serum (Berroukche et al., 2016). High fat diet is source of oxidative stress which induced metabolic disorders (Berroukche $\boldsymbol{e t}$ al., 2015). The most important thing in this study is to know whether or not vitamin $\mathrm{C}$ and Cyrana cardunculus, as medicinal plant, have different preventive effects against metabolic alterations caused by a diet rich in carbohydrates, fats and calories (or cafateria diet).

Treatment of animals, exposed to high-fat-diet, with a lower dose of vitamin C $(200 \mathrm{mg} / \mathrm{mL})$ showed a slightly increase in blood glucose, triglycerides and total cholestrol serum. These experiments are similar to study conducted by Magdy $\boldsymbol{e t}$ al. (2016). Hepatic damage was revealed in the current study, through a rising of the liver enzyme activities namely GOT and GPT.

In agreement, vitamin $\mathrm{C}$ induced hepatotoxicity has been documented by Naidu (2001) and Zervos et al. (2011). In the present study, it was found that GOT and GPT serum increased significantly in rats treated with vitamin $\mathrm{C}$, this finding is in agreement with that of Hsu et al. (2001) who suggested higher levels of hepatic transaminases. Vitamin $\mathrm{C}$ is widely used as an analgesic and antipyretic agent. It is safe at recommended doses. However, vitamin $\mathrm{C}$ overdose can trigger liver tissue damage (Blieden et al., 2014). Intake of vitamin C, or ascorbic acid for maintenance and stability of normal health was a subject of controversy since 5 decades (Nandi et al, 1973). Vitamin C Toxicity caused by high concentrations has been widely reported in animal cells (Margis-Pinheiro and Silveira , 2018). Excess vitamin $\mathrm{C}$ is excreted from the body as oxalate, a waste product. A high vitamin $\mathrm{C}$ intake increases the amount of oxalate in urine, thus increasing the risk of developing kidney stones (Assimos, 2004). To date in the litterature, no association has been found between vitamin $\mathrm{C}$ consumption and hyperglycaemia or hypercholesterolemia (Gillani et al, 2017).

This study revealed that CCS and CCL aqueous extracts, orally administered to animals at dose $125 \mathrm{mg} / \mathrm{L}$, reduced significantly blood glucose, triglycerides, total cholesterol and liver enzymatic activities of transaminases. According to the nutritionists, artichoke has a chemical composition characterized by high level of phenolic compounds (Caffeoylquinic acids) and flavonoids (anthocyanins) (De Falco et al, 2015). Artichoke composition revealed $7 \%$ of carbohydrates, $3 \%$ of proteins and $0.3 \%$ of lipids. The artichoke's high content of fiber (5.5\%) makes this plant a potential functional food and a traditional medicine (Lattanzio et al, 2009; De Falco et al, 2015).

Previous animal studies suggested preventive effects of Cynara cardunculus leaves aqueous extract against oxidative stress (Rezazadeh et al., 2017). Artichoke is a rich source of caffeoylquinic acids and hydroxycinnamic acids (phenolic acids) and its preventive indication can be associated to severa bioactive compounds that together trigger off synergic pharmacologic effects (Garbetta et al., 2014).

The edible parts of artichoke also contain sesquiterpenes, which help to protect the liver, decrease blood glucose and cholesterol levels, have antitumor effects, and increase the bile secretion from liver during digestive process (Jacociunas et al, 2013). Artichoke, or Cynara cardunculus, has a potential antioxidant activity and its bioactive molecules have a scavenging power and stabilize reactive oxygene species (ROS) or free radicals generated through the lipid peroxidation of cell membrane (Impellizzeri et al, 2012).

Our results confirmed that artichoke extracts (CCS and CCL) have antioxidan activities. Results, obtained in this study, are in agreement with those showed by El-Boshy et al. (2017). Authors revealed the hypoglycemic, hypolipidemic and hepatoprotective effects of CCS and CCL decoctions at a concentration of 125 $\mathrm{mg} / \mathrm{L}$. Previous studies on preventive activities, conducted on different aerial plant parts of artichoke, showed various polyphenol profiles with differences of concentrations and composition (Mahmoudi et al., 2007). Protective effects of CCS and CCL are due to the richness of Artichoke in phenolic compounds, flavonoids and sesquiterpenes which are mainly associated to their potential synergetic molecular actions. The oxidative stress, induced by high-fat-diet, generates reactive oxygenated species (ROS), or free radicals, responsible of cell membrane lipid peroxidation. Therefore, CCS and CCL aqueous extracts improve antioxidant process and inhibit free radical generation and the lipid peroxidation.

Table 1 Effects of vitamin C and Cyrana cardunculus plant parts (stems and leaves) on biochemical parameters in rats fed with high-fat-diet

\begin{tabular}{|c|c|c|c|c|c|c|}
\hline $\begin{array}{l}\text { Parameters } \\
(\text { Mean } \pm \text { SEM) }\end{array}$ & Controls & HFD & HFD-VC & HFD-CCS & HFD-CCL & $P$-value \\
\hline Body weight (g) & $141 \pm 2.5$ & $172.3 \pm 3.4$ & $216.6 \pm 2.2$ & $176.9 \pm 1.6$ & $173.2 \pm 2.0$ & $<0.01$ \\
\hline Blood glucose (g/L) & $1.02 \pm 0.05$ & $1.43 \pm 0.08$ & $1.32 \pm 0.02$ & $0.84 \pm 0.03$ & $0.85 \pm 0.02$ & $<0.01$ \\
\hline Triglycerides (g/L) & $0.64 \pm 0.08$ & $0.94 \pm 0.09$ & $0.86 \pm 0.08$ & $0.64 \pm 0.03$ & $0.52 \pm 0.02$ & 0.009 \\
\hline Total cholesterol (g/L) & $1.17 \pm 0.2$ & $1.7 \pm 0.05$ & $1.3 \pm 0.05$ & $1.01 \pm 0.07$ & $0.89 \pm 0.03$ & 0.004 \\
\hline Cholesterol-HDL (g/L) & $0.63 \pm 0.03$ & $0.46 \pm 0.06$ & $0.76 \pm 0.02$ & $1.21 \pm 0.05$ & $1.42 \pm 0.05$ & $<0.01$ \\
\hline GOT (IU/L) & $47.3 \pm 3.7$ & $68.6 \pm 2.9$ & $112.2 \pm 1.7$ & $22.6 \pm 0.5$ & $12.6 \pm 0.7$ & $<0.001$ \\
\hline GPT (IU/L) & $12 \pm 0.4$ & $34.6 \pm 2.0$ & $73.6 \pm 3.3$ & $19.6 \pm 0.5$ & $10.3 \pm 0.6$ & $<0.01$ \\
\hline
\end{tabular}

SEM: standard error of mean - HFD: high fat diet - VC: vitamin C - CCS: Cyrana cardunculus stems - CCL: Cyrana cardunculus leaves - HDL: high density lipoproteins - GOT: glutamic oxaloacetic transaminase - GPT: Glutamic pyruvic transaminase - IU: international unity. 


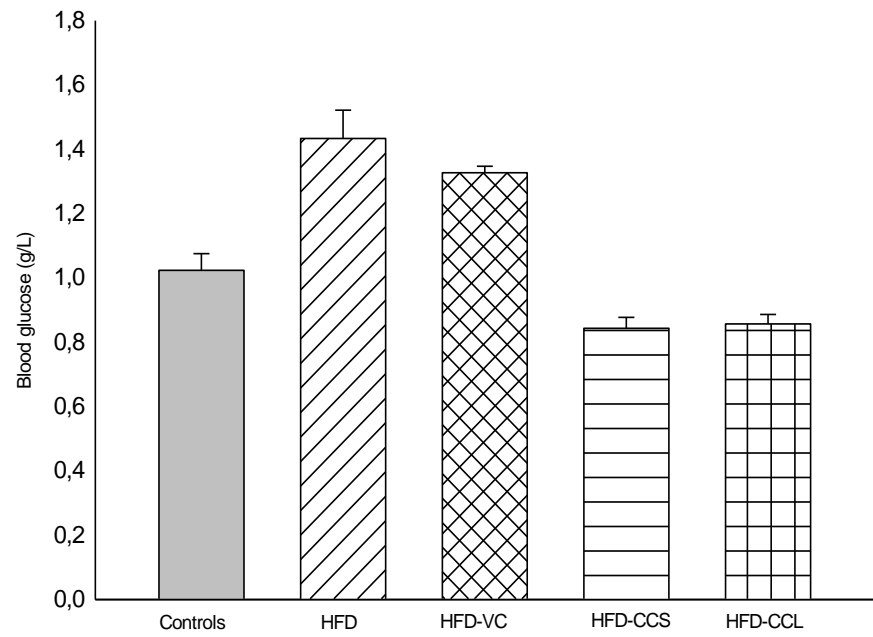

Figure 6 Variation of blood glucose in rats fed with high-fat-diet and treated with vitamin $\mathrm{C}$ and Cyrana cardunculus

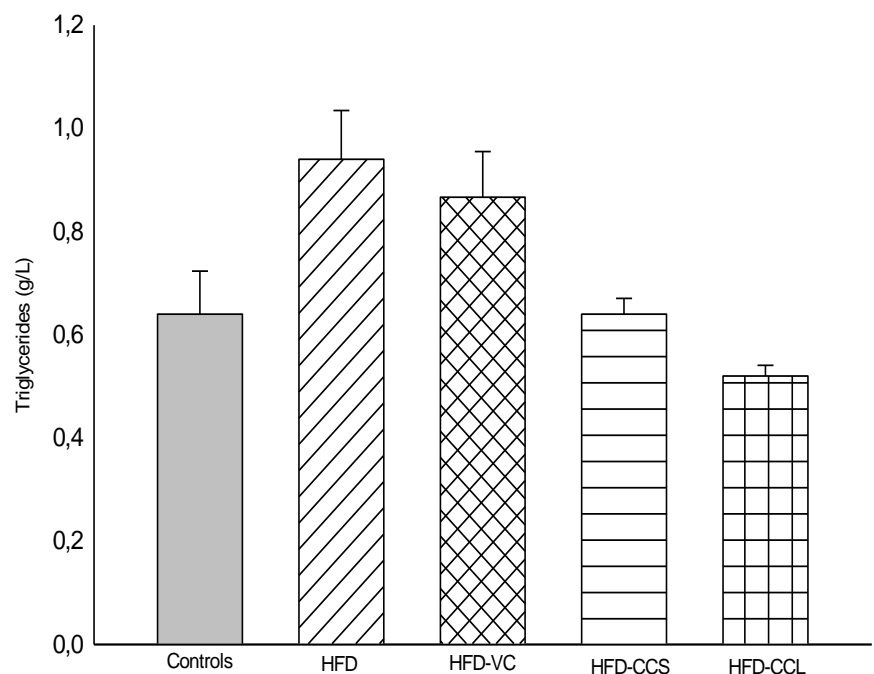

Figure 7 Variation of triglycerides serum in rats fed with high-fat-diet and treated with vitamin $\mathrm{C}$ and Cyrana cardunculus

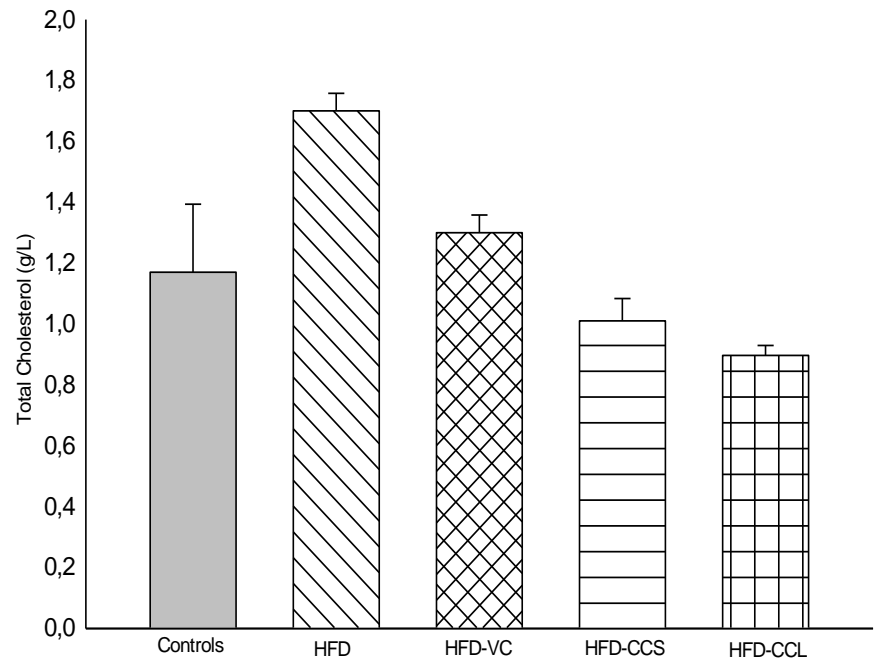

Figure 8 Variation of total cholesterol serum in rats fed with high-fat-diet and treated with vitamin $\mathrm{C}$ and Cyrana cardunculus

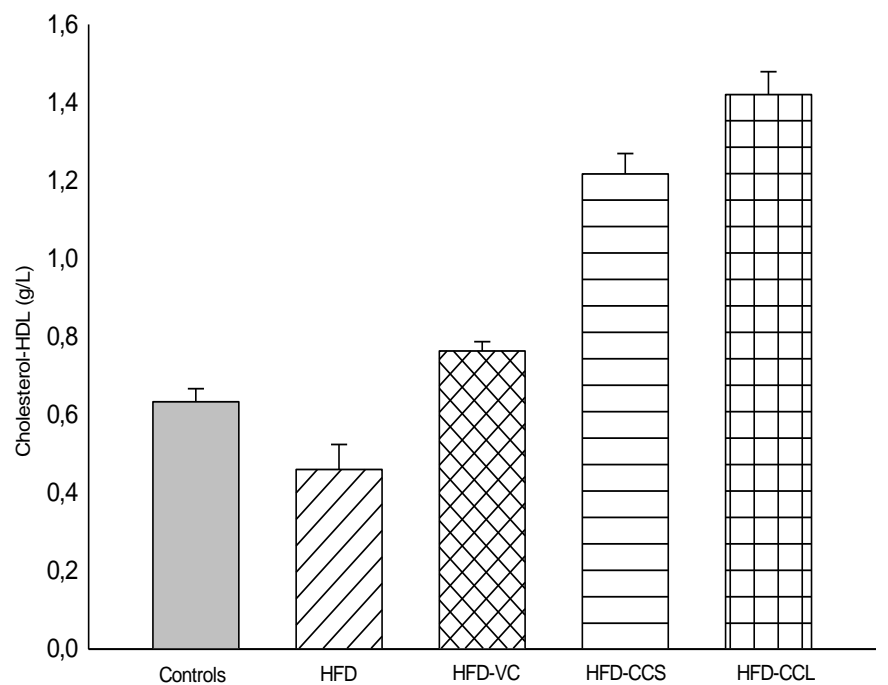

Figure 9 Variation of cholesterol-HDL serum in rats fed with high-fat-diet and treated with vitamin $\mathrm{C}$ and Cyrana cardunculus

\section{CONCLUSION}

High-fat-diet induces an oxidative stress and metabolic disorders as obesity, type 2 diabetes and cardiovascular diseases. Treatment with Artichoke aqueous extract, in our study, shows protective effects. Cynara cardunculus shows beneficial effects against biochemical disorders induced by high-fat-diet better than vitamin $\mathrm{C}$ supplement. Stem and leave decoctions indicate complementary activities respectively hypoglycemic and hypocholesterolemic. Therefore, artichoke as food supplementation could be a potential tool to enhance the prevention against chronic metabolic diseases.

Acknowledgments: Authors would like to thank the paramedical team of the biological laboratories of Saida hospital, Algeria.

\section{REFERENCES}

ANIMAL TOXINS. The median lethal dose, the measurement indicator venom? http://toxinesanimales.blogspot.com/p/la-dose-letale-mediane.html (website accessed July 16, 2018)

ASSIMOS D.,G. 2004. Vitamin C Supplementation and Urinary Oxalate Excretion. Rev Urol., 6(3), 167.

BASTAKI, S. 2005. Diabetes mellitus and its treatment. International Journal of Diabetes and Metabolism, 13, 111-134.

BERROUKCHE, A., ANTEUR, D., TAHIRI, Y., HALIMI B. 2015. Comparative study between effects of ethanolic extract of Olea europaea leaves and metformine on lipid profile in streptozotocine-induced diabetic rats. Journal of International Research in Medical and Pharmaceutical Sciences, 4 (1), 11-16. BERROUKCHE, A., ATTAOUI, A., LOTH, M. 2016. Comparative study between effects of ethanol extract of Zingiber officinale and Atorvastatine on lipid profile in rats. Journal of Pharmacognosy and Phytotherapy, 8(8), 152-162 Doi: 10.5897/JPP2015.0369.

BLIEDEN M., PARAMORE L.,C., Shah, D. 2014. A perspective on the epidemiologyof acetaminophen exposure and toxicity in the United States, Expert. Rev. Clin. Pharmacol., 3, 341-348.

CHO, A., JEON, S., KIM, M., YEO, J., SEO, K., CHOI, M., et al. 2010 Chlorogenic acid exhibits anti-obesity property and improves lipid metabolism in high-fat diet-inducedobese mice. Food and Chemical Toxicology, 48, 937-943. https://doi.org/10.1016/j.fct.2010.01.003.

DE FALCO B., INCERTI G., AMATO M., LANZOTTI V. 2015.Artichoke: botanical, agronomical, phytochemical, and pharmacological overview. Phytochem Rev., published online, DOI 10.1007/s11101-015-9428-y.

El-BOSHY, M., ASHSHI, A., GAITH, M., QUSTY, N., BOKHARY, T., ALTAWEEL, N., ABDELHADY, M. 2017. Studies on the protective effect of the artichoke (Cynara scolymus) leaf extract against cadmium toxicity-induced oxidative stress, hepatorenal damage, and immunosuppressive and hematological disorders in rats. Environ Sci Pollut Res. http: // DOI 10.1007/s11356-017-8876

FRITSCHE J, BEINDORFF CM, DACHTLER M et al (2002) Isolation, characterization and determination of minor artichoke (Cynara scolymus L.) leaf extract compounds. Eur Food Res Technol, 215,149-157. https://doi.org/10.1007/s00217-002-0507-0 
GARbETTA, A., CAPOTORTO, I., CARDINAli, A., D’ANTUONO, I., LINSALATA, V., Pizzi, F., Minervini, F. 2014. Antioxidant activity induced by main polyphenols present in edible artichoke heads: influence of in vitro gastrointestinal digestion. Journal of Functional foods, 10, 456-464 https://doi.org/10.1016/i.jff.2014.07.019

GILLANI S.,W. SULAIMAN S.,A.,S., MOHAMED ABDUL M., I., BAIG M.,R. 2017. Combined effect of metformin with ascorbic acid versus acetyl salicylic acid on diabetes-related cardiovascular complication; a 12-month single blind multicenter randomized control trial. Cardiovascular Diabetology, 16,103.

HSU, D., HSU, C., HUANG, B., LIU, M. 2001. Abamectin effects on aspartate aminotransferase and nitric oxide in rats. Toxicology, 165 (2-3), 189-193. https://doi.org/10.1016/S0300-483X(01)00434-6

IMPELLIZZERI, D., ESPOSITO, E., MAZZON, E., PATERNITI, I., DI PAOLA, R., BRAMANTI, P., et al.2012. The effects of a polyphenol present in olive oil, oleuropein aglycone, in an experimental model of spinal cord injury in mice. Biochemistry Pharmacology, 83, 1413-1426.

INRA.2006.Second National Report on the State of Plant Genetic Resources.

INSTITUTE OF MEDICINE. Food and Nutrition Board. Dietary Reference Intakes for Vitamin C, Vitamin E, Selenium, and Carotenoids. Washington, DC: National Academy Press, 2000.

JACOCIUNAS, L. V., ANDRADE, H. H. R., LEHMANN, M., ABREU, B. R. R., FERRAZ, A. B. F., SILVA, J., et al.2013. Artichoke induces genetic toxicity in the cytokinesis-block micronucleus (CBMN) cytome assay. Food and Chemical Toxicology, 55, 56-59.

LATTANZIO V., KROON P.,A., LINSALATA V., et al.2009. Globe artichoke: a functional food and source of nutraceutical ingredients. J Funct Food 1, 131144.

LOMBARDO, S., PANDINO, G., MAUROMICALE, G., KNODLER, M., CARLE, R., \& SCHIEBER, A. 2010. Influence of genotype, harvest time and plant part on polyphenolic composition of globe artichoke [Cynara cardunculus L. var. scolymus (L.) Fiori]. Food Chemistry, 119, 1175-1181. https://doi.org/10.1016/j.foodchem.2009.08.033

MAGDY, B., W., El_SAYED MOHAMED, F., SELEEM AMIN, A., SARHAN RANA, S. 2016. Ameliorative effect of antioxidants (vitamins C and E) against abamectin toxicity in liver, kidney and testis of male albino rats. Journal of Basic \& Applied Zoology, 77, 69-82. https://doi.org/10.1016/j.jobaz.2016.10.002

MAHMOUDI, S., KHALI, M., MAHMOUDI, N. 2013. Study of phenolic compound extraction from different parts of the artichoke flower (Cynara scolymus L.). Nature \& Technology, 9, 35-40.

NAIDU, K., A. 2003. Vitamin C in human health and disease is still a mystery. An overview. Nutr. J., 2, 7-16. https://doi.org/10.1186/1475-2891-2-7

MARGIS-PINHEIRO M., SILVEIRA J.,A.,G. 2018. Ascorbic acid toxicity is related to oxidative stress and enhanced by high light and knockdown of chloroplast ascorbate peroxidases in rice plants. Theoretical and Experimental Plant Physiology, 30 (1), 41-55.

NANDI B.,K., MAJUMDER A.,K.,, SUBRAMANIAN N., CHATTERJEE I., B

1973 ,Effects of Large Doses of Vitamin C in Guinea Pigs and Rats. Journal of

Nutrition, J. Nutr. 203: 1688-1695.

PANDINO, G., LOMBARDO, S., MAUROMICALE G. 2011. Profile of polyphenols and phenolic acids in bracts and receptacles of globe artichoke (Cynara cardunculus var. scolymus) germplasm. J. Food, Compos, Anal., 24, 148-153. https://doi.org/10.1016/j.jfca.2010.04.010

PEREZ-GARCIA, F., ADZET, T., CANIGUERAL, S. 2000. Activity of artichoke leaf extract on reactive oxygen species in human leukocytes. Free Radic. Res. 33 (5), 661-665. https://doi.org/10.1080/10715760000301171

POUTEAU, E., TURNER, S., APRIKIAN, O., HELLERSTEIN, M., MOSER, M., DARIMONT, C., FAY, L., B., MACE, K. 2008. Time course and dynamics of adipose tissue development in obese and lean Zucker rat pups. International Journal of Obesity, 32, 648-657. https://doi.org/10.1038/sj.ijo.0803787

RAMOS, P., A.,B., GUERRA, A.,R., GUERREIRO O.2013. Lipophilic extracts of Cynara cardunculus L. var. altilis (DC): a source of valuable bioactive terpenic compounds. J. Agric. Food. Chem., 61, 8420-8429. DOI: 10.1021/jf402253a

REZAZADEH, K., ALIASHRAFI, S., ASGHARI-JAFARABADI, M. EBRAHIMI-MAMEGHANI, M. 2017. Antioxidant response to artichoke leaf extract supplementation in metabolic syndrome: A double-blind placebocontrolled randomized clinical trial. Clinical Nutrition, 37 (3), 790-796. https://doi.org/10.1016/j.clnu.2017.03.017

ROSSONI, G., GRANDE, S., GALLI, C. 2005. Wild artichoke prevents the ageassociated loss of vasomotor function. J. Agric. Food. Chem., 53 (26), 1029110296. DOI: $10.1021 /$ jf052499s

UZUN, F., G., KALENDER, S., K., DURAK, D., DEMIR, F., KALENDER, Y. 2009. Melathion-induced testicular toxicity in male rats and the protective effect of vitamins C and E. Food. Chem. Toxicol, 47 (8), 1903-1908. https://doi.org/10.1016/j.fct.2009.05.001

YUAN, G., DAI, S., YIN, Z., LU, H., JIA, R., JIAOXU, J., SONG, X., LI, L., SHU, Y., ZHAO, X. 2014. Toxicological assessment of combined lead and cadmium: acute and sub-chronic toxicity study in rats. Food Chem. Toxicol., 65, 260-268. https://doi.org/10.1016/i.fct.2013.12.041

ZERVOS, I.,A., NIKOLAIDIS, E., LAVRENTIADOUS, S.,N., TSANTARLIOLOU, M.,P., ELEFTHERIADOU, E.,K., PAPAPANAGITOUS,
E.,P., FlETOURIS, D.,J., GEORGIDIS, M., TAITZOGLOUS, I., A. 2011 Endosulfan induced lipid peroxidation in rat brain and its effect on L-PA and PAI-1: ameliorating effect of vitamin C and E. J. Toxicol. Sci., 36 (4), 423-433. https://doi.org/10.2131/jts.36.423 